\title{
HOW TO READ AUSTIN
}

\author{
Marina Sbisà
}

\begin{abstract}
The goal of this paper is a reassessment of the contributions provided by John L. Austin's book "How to Do Things with Words" to pragmatics. It discusses some assumptions belonging to the received reading of the volume, as regards its aim and structure, the conceptions of illocution and of perlocution, and the alleged exclusion of "non-seriousness". Against the received reading, it is argued that "How to Do Things with Words" is structured as a proof by contradiction of the claim that all speech should be considered as action, that in illocution a major role is played by the conventionality of effects, that perlocution presupposes a conception of action as responsibility, and that Austin had reasons not to deal with "nonseriousness" in detail, albeit recognizing the issue as relevant to the study of the uses of language. In the conclusions, the tenets attributed to Austin are neither crtiticized nor defended, but an attempt is made to say what are their implications for research into language use and for philosophy.
\end{abstract}

Keywords: J.L. Austin; Illocutionary act; Perlocutionary act; Convention; Action.

\section{Four assumptions to be disputed}

In this paper I consider what contributions are offered to pragmatics (in a broad sense, ranging from philosophy to interdisciplinary research into language use) by John L. Austin's famous booklet "How to Do Things with Words" (1962) It might seem the question is otiose: Everybody who has ever been concerned with pragmatics knows that "How to Do Things with Words" (henceforth: HTW) proposes first the performative/constative distinction, then the distinction between meaning and force and the distinction between illocutionary and perlocutionary acts. But if we reflect on those distinctions, it may appear that it is not so clear what their point is. A lot of literature has been produced for decades on force vs. meaning or on perlocution vs. illocution, but has not shed final light on the job these distinctions were originally designed for. It is also uncertain what relationship there is in HTW between those distinctions and the performative/constative distinction, from which they appear to stem. And if we even superficially consider Austin's claims, terminology and definitions, as distinct from subsequent developments of speech act theory, we easily realize that they have hardly ever been put to use either in theoretical debates or in analyses of discourse and conversation.

Why is this so? First of all, HTW is a misleading book, the structure of which is easily misunderstood. There have been early misreadings of it, which have been extremely influential. Moreover, Austin's original proposal has often been conflated with subsequent versions of speech act theory, that of John Searle in particular.

I believe therefore that there is still room for a reassessment of the contributions provided by HTW to pragmatics; obviously, this reassessment requires a more careful 
reading of the book. As a contribution to such a re-reading, I will discuss four assumptions belonging to the "received reading" of HTW:

(1) that HTW was written in pursuit of performatives;

(2) that for Austin, performing an illocutionary act amounts to producing the uptake of the meaning and force of the utterance;

(3) that for Austin, performing a perlocutionary act amounts to using language to produce consequences;

(4) and finally, that Austin's theory unduly excludes “non-serious” speech acts.

These assumptions are incorrect and prevent us from understanding the actual contributions provided by the volume.

\section{In pursuit of performatives?}

Let us start with the first assumption: That HTW was written "in pursuit of" performatives.

People have often thought that in HTW, Austin proposes the performative/ constative distinction, which he subsequently abandons in favour of the less clear-cut locutionary/ illocutionary/ perlocutionary distinction. For example, Max Black writes in his review of HTW : “The late John Austin's William James Lectures might well have borne the subtitle 'In Pursuit of a Vanishing Distinction'”(1963: 217). Even a supporter of Austin's conclusion that the distinction does not hold because assertions are performatives too (hence, illocutionary acts), like L.W. Forguson, seems to assume that Austin conducted his inquiry in pursuit of the performative/constative distinction and then changed his mind (Forguson 1966). But there is no trace of a change of mind in the various sets of notes forming the manuscript. ${ }^{1}$ The earliest set of notes (1951) already contains the Locutionary-Illocutionary-Perlocutionary distinction and considers assertions as illocutionary acts. Moreover, some early preparatory notes hint at "happygo-lucky" uses of performative utterances, which Austin disapproves of and which are characterized by an exclusive opposition between having meaning and performing an action.

We may say that in HTW, from the very start the performative/constative distinction plays an instrumental role. The analysis of performative utterances provides a first approach to actions performed in speech and therefore to the kinds of things that are done by illocutionary acts. Constatives are just a straw man, to be replaced with an analysis of assertion as an illocutionary act (such as the one outlined further on in the volume, in chapter 11). Confirmation of this reading is scattered throughout initial lectures, in hints that make sense only in the light of the main thesis which will be revealed later in the book, i.e. that all speech should be considered as action.

So, HTW appears as a complex argument in support of the claim that all speech should be considered as action and, more specifically, that speech can be described as

${ }^{1}$ The manuscript from which the printed text of Austin's William James Lectures was drawn is conserved in Oxford at the Bodleian Library. It comprises various sets of notes written from 1950 to 1955, among which those used by Austin for lecturing at Harvard. I consulted it several times (e.g., while collaborating with James O. Urmson at the second revised edition of the volume) and most recently in 2005. 
the performing of actions of the same kind as those performed by means of performative utterances. This complex argument has the form of a proof by contradiction: The thesis proposed at the beginning is the opposite of the intended one and its refutation serves as a proof of the intended thesis.

To be more schematic: In HTW we have a Hypothesis $(\boldsymbol{P})$ "Some utterances are performative", a Thesis $(\boldsymbol{A})$ "All of our utterances perform actions of the same kind as those performed by performative utterances” and a proof by contradiction, which goes approximately like this:

Suppose that $\boldsymbol{A}$ does not hold (not $\boldsymbol{A}$ ): since some utterances are performative $(\boldsymbol{P})$, it should be possible to distinguish them sharply from constative utterances (if $P$ and not $A$, then $P / C$ );

But the performative/constative distinction is flawed, and therefore not $\boldsymbol{A}$ does not hold;

So the supposition that $\boldsymbol{A}$ does not hold is false, and therefore, $\boldsymbol{A}$ holds.

Of course, the correctness of this argument depends on the correctness of the subarguments against the performative/constative distinction. I recall that there are two, the former consisting of an attempt to show that assertions too have felicity conditions (HTW45-52, 137-39), the latter claiming that any utterance can be reformulated as an explicit performative (see e.g. HTW 67-68, 85, 134-36). They are far from unproblematic, but it is not my task here to evaluate them; I only want to point out their function within Austin's project.

The main point of HTW, as it emerges from the reading I am proposing, is the discovery of illocution as a dimension of language use, which is fully general (therefore involving criticism of the ideal of assertion as purely constative), and intermediate between saying and producing extralinguistic consequences. ${ }^{2}$ We are going to have a closer look at what exactly was so "discovered" in the discussion of the other assumptions belonging to the received reading of HTW, the second one in particular, namely, that performing an illocutionary act amounts to producing the hearer's uptake of the meaning and the force of the utterance.

\section{Illocutionary acts and their effects}

Illocutionary acts are characterized by most authors in speech act theory as acts, whose effect consists in the production of the hearer's uptake. This idea is to be found in a paper by Peter Strawson, "Intention and convention in speech acts" (1964), where uptake is considered as the only effect that every felicitous illocutionary act must have. An analogous idea can be found in early work by John Searle, who defines the "illocutionary effect" as "the hearer understanding the utterance of the speaker"(1969: 47). But that is not an idea of Austin's.

2 Although Austin's discovery of illocution has been acknowledged in the subsequent development of speech act theory, the initial bias towards reading HTW as proposing and self-defeatingly discussing the performative/constative distinction is still in the background and has influenced the reception of what Austin says about illocution, often making his criticism of assertion go unnoticed. That is was among Austin's goals to criticize the ideal of assertion as purely constative has been recently stressed by Crary (2002). 
Of the uptake effect, Austin writes: "Unless a certain effect is achieved, the illocutionary act will not have been happily, successfully performed [...]. I cannot be said to have warned an audience unless it hears what I say and takes what I say in a certain sense [...]. So the performance of an illocutionary act involves the securing of uptake." (HTW116-17). Now, according to Strawson, Austin's words “Unless a certain effect is achieved..." imply that no other effect than uptake is necessarily connected to the performance of an illocutionary act, i.e. a felicitous illocutionary act may have uptake as its only effect. This reading of Austin has allowed for the reinterpretation of illocutionary force as some kind of Gricean speaker meaning. As we know, this reinterpretation has been developed in mainstream versions of speech act theory such as those of Searle (1969, 1979) and of Bach and Harnish (1979).

But Austin merely meant uptake to be a necessary condition for the successful achievement of the core effect of the illocutionary act, which according to him, goes beyond mere understanding. He describes such a core effect thus: "The illocutionary act 'takes effect' in certain ways, as distinguished from producing consequences in the sense of bringing about states of affairs in the 'normal' way, i.e. changes in the natural course of events...” (HTW117). This passage of Austin's has often been disregarded by speech act theorists and is in fact rather mysterious. What sort of an effect is this, which does not consist of bringing about states of affairs in the "normal" way? Note that the "normal" way is by natural causation: That is, through the production of changes in the natural course of events. So what is the "non-normal" way? Austin gives only one example, and not a very helpful one: The illocutionary act of naming a ship. The effect of such an illocutionary act is, first, that the ship is given a name and second, that certain subsequent acts (such as referring to the ship by a different name) will be out of order.

The example may seem not to be representative: In fact naming a ship is not a common, everyday illocutionary act such as promising, commanding, warning, apologizing, etc. Nevertheless, we can use the example to characterize the kind of effect that, according to Austin, illocutionary acts "take". The effect of the naming of a ship consists of a change not in the natural course of events but in norms, that is, in something belonging to the realm of social conventions; and it is an effect that comes into being thanks to the hearer's uptake, that is, insofar as it is clear to the relevant audience that the speaker has (felicitously) named the ship. It is not rash to identify such an effect with the "conventional effect" which the illocutionary act, as an accepted conventional procedure, is designed to produce. In fact Austin's Felicity Condition A1, the first in his list of felicity conditions for performative utterances, reads: "There must exist an accepted conventional procedure having a certain conventional effect, that procedure to include the uttering of certain words by certain persons in certain circumstances..." (HTW 14; my emphasis).

It could be objected that this condition applies to performative utterances and not to illocutionary acts: But in commenting on illocutionary acts in the second part of HTW, Austin clearly shows that the doctrine of Infelicities exposed in the first chapters should apply to them (see e.g. HTW106). This is further evidence that Austin maintained that illocutionary acts have conventional effects.

We may say that Austin was wrong in generalizing from the naming of a ship example. But we have to admit that his claim about the conventional character of the core effect of illocutionary acts is put forward as a general claim. This suggests that appropriate support for Austin's claim that illocutionary acts are conventional should 
come from the conventionality of their effects, rather than from the conventionality of the means by which they are performed.

In the debate over the conventionality of illocutionary acts, attention has been paid only to the means for performing the illocutionary act and not to the nature of its effect. Since linguistic means are only trivially conventional, there seemed to be no reason for calling "conventional" those illocutionary acts which do not involve extralinguistic rituals or social institutions. But we can make better sense of Austin's claim that all illocutionary acts are conventional if we focus attention on the conventionality of effects. In the reading of HTW I am proposing, all illocutionary acts are conventional primarily because they all have conventional effects.

This in turn raises various problems. First, we should be able to describe the conventional effects of all types of illocutionary acts, but for many of them such a description is difficult and Austin has not dealt with this descriptive problem exhaustively, although several suggestions can be gathered from his work. Second, we should also reflect on what makes an effect "conventional".

I will not discuss the first problem here, although I have ideas about how to handle it. ${ }^{3}$ As to the second problem, I would like to propose two conditions that an effect should satisfy in order to be conventional. First, it should be "defeasible" (that is, liable to turning out null and void under certain conditions). Non-conventional, material or "natural" effects either are produced or not: The states of affairs they consist of can be further modified, but not just annulled. Second, the effect should be achieved in some way other than by producing a change in the natural course of events. The most obvious (if not the only) candidate is the production of an effect thanks to the agreement on the part of the relevant participants on which act it is that has been performed. By "agreement" I do not mean explicit, metacommunicative agreement; in most cases implicit or even tacit agreement is enough. These two conditions can be traced back to Austin: The former to his insistence, in his preparatory notes for HTW, on the idea of "making undone"; the latter to the very fact that he deems uptake to be a necessary condition for successful performance.

In his preparatory notes, Austin refers more than once to Aristotle's remark that since what is past is not capable of not having taken place, nobody can make undone what has been done: On this view, the effects of our actions are irreversible. ${ }^{4}$ But, Austin notices, the acts performed by means of performative utterances (therefore, illocutionary acts) appear to be an exception, since they may turn out to be null and void if certain conditions are found not to be satisfied. This does not mean that what was actually done did not really take place, or that nothing at all was done by the performer of the infelicitous act: In fact, we have ways of redescribing null acts in terms of the performance of different acts and we may say that it is those acts which really took place. But the discovery of infelicity may make the illocutionary act undone insofar as the bringing about of its conventional effect is concerned. The words were uttered, the

${ }^{3}$ The search for ways of describing the conventional effects of illocutionary acts has inspired much of my work in speech act theory. See Sbisà (1984, 2001, 2006).

4، It is to be noted that nothing that is past is an object of choice, e.g. no one chooses to have sacked Troy; for no one deliberates about the past, but about what is future and capable of being otherwise, while what is past is not capable of not having taken place; hence Agathon is right in saying:

'For this alone is lacking even to God,

To make undone things that have once been done'”

(Aristotle, Nichomachean Ethics, VI, 2, English translation by David Ross, Oxford, Oxford University Press, 1925). 
conventional effect was supposed to be there, it was even acted upon for a while; but once we discover the infelicity, we realize that the conventional effect never really came into being. Subsequent agreement about the nullity of the act overcomes the former, provisional agreement about its performance. It should be noted that illocutionary effects are also cancellable, that is, they can, once achieved, be abrogated or superseded by acts bringing about opposite conventional effects (for example, an assertion can be withdrawn, or what was prohibited may be permitted). But what Austin's remarks on "making undone" attribute to illocutionary acts, namely that which I have called "defeasibility", goes beyond the cancellability of achieved effects, since it affects the conventional effect in its making, and therefore the act which brings it about.

As to uptake, since it involves the agreement of the participants (often implicit or even tacit) upon what has been done, its role with respect to the conventionality of illocutionary effects is to distinguish them as non-normal, conventional effects from normal, causal ones. Dependence on uptake is characteristic of the former. If illocutionary acts are successfully performed only when they produce the hearer's uptake, this is because (1) illocutionary acts have conventional effects and (2) these come into being thanks to the participants' agreement. So, in Austin, the uptake requirement is not in competition with the alleged conventional nature of illocutionary acts, as in the received reading of HTW: Rather, the opposite holds.

\section{What is a perlocutionary act?}

The next assumption I want to discuss is that performing a perlocutionary act amounts to using language to produce consequences. This assumption does not misrepresent Austin's notion of perlocution, but is misleading nevertheless, in two main ways. It may be taken to imply that all production of consequences beyond the production of the hearer's uptake is perlocutionary. Or it may be taken to imply that, in order to perform a perlocutionary act, a speaker must intend to produce certain consequences: In other words, that his or her speech act must have a perlocutionary goal. Both these assumptions yield incorrect interpretations of Austin's theoretical proposal.

Let us examine the former issue more closely. If the assumption that performing a perlocutionary act amounts to using language to produce consequences is meant to imply that all production of consequences beyond the production of the hearer's uptake is perlocutionary, this is again a misunderstanding of Austin, complementary to the misinterpretation of the illocutionary act I have just discussed. In fact, if (with Austin) it is admitted that illocutionary acts have conventional effects, these may have further consequences at the conventional level, and therefore, not all consequences of a speech act are perlocutionary. Moreover, the conventional effect of the illocutionary act, although not precisely a "consequence" (but an outcome or result), itself goes beyond the production of the hearer's uptake. The border between Illocution and Perlocution runs between conventional effects and changes in the natural course of events: The former are cancellable and defeasible, the latter are not, and if they are brought about by means of a speech act, their production amounts to a perlocutionary act. In fact, the distinction between Illocution and Perlocution is at all possible only if a difference between natural and conventional effects is accepted.

The assumption that performing a perlocutionary act amounts to using language to produce consequences may also be taken to imply that, in order to perform a 
perlocutionary act, a speaker must intend to produce the relevant consequences. Is then the perlocutionary act to be identified with a speech act having a perlocutionary goal? Of course not, for two reasons. Also unintended consequences are considered by Austin as constitutive of perlocutionary acts (HTW 106, 118). And conversely, having a perlocutionary goal is not sufficient for a speech act to be successful as the perlocutionary act achieving that goal: If a speech act has a perlocutionary goal but fails to achieve it, there is no corresponding perlocutionary act.

At this point, an objection can be raised to the internal consistency of the notion of a perlocutionary act: How can a speaker ever perform a perlocutionary act, if what is needed for a perlocutionary act to be performed is not an act of the speaker, but one of the listener? This objection (due to Gu 1993) is misguided but interesting, since it draws attention to what we may call the "invisibility" of the perlocutionary act, that is, the fact that it does not consist of any physical or psychological gesture of the speaker (such as a bodily movement or the formation of a mental state). Insofar as the speaker's behaviour is concerned, there is nothing more in the perlocutionary act than there was in the illocutionary or for that matter, in the locutionary. Still, Austin insisted in presenting it as an act of the speaker. What does the perlocutionary act consist of, according to his view?

The source of most misunderstandings about Austin's conception of the perlocutionary act lies in his conception of action. Austin has been read in the framework of the mainstream view of action, according to which actions basically are, or can be identified with, gestures of an individual, intentionally performed. I surmise that Austin was presupposing a different framework. His view of action, as it can be reconstructed from HTW as well as from his papers in the theory of actionAustin 1956, 1957, 1966), was non-reductionist and description-related. By this I mean that according to him, there is no reduction of the different effects of one and the same gesture to one and the same basic action, rather, descriptions of these different effects pick out different actions. We perform more than one action with one and the same gesture, insofar as that produces more than one effect. ${ }^{5}$ So, Austin seems to have considered agency as justly ascribed responsibility: There is agency whenever it is fair to ascribe to an agent responsibility for a certain outcome. ${ }^{6}$

It is interesting to notice that while Austin's speech act theory did not evolve significantly after 1955, between 1955 and 1959 he worked more on the theory of action. While it has been often thought that his speech act theory is no more than an incomplete outline because he died before really developing it, I would say that his truly incomplete work is that regarding the theory of action. This incompleteness affects his speech act theory indirectly, because a speech act theory must presuppose some analysis of action.

We may say that in the sense of action which I have attributed to Austin, a perlocutionary act can certainly be an action of the speaker, even if no gesture of the speaker specifically corresponds to it. If agents "do" whatever they may be justly ascribed (at least partial) responsibility for, a perlocutionary act is performed whenever

\footnotetext{
${ }^{5}$ The only attempt to develop a view of action of this non-reductionist, description-related kind I am aware of is Goldman (1970).

${ }^{6}$ The notion of responsibility I am using here to characterize Austin's view of action does not by itself amount to moral responsibility: it is meant to apply to actions independently of their being blameworthy or blameless. A similar use of "responsibility" has been made, also in connection with Austin’s philosophy of action, by Yeager (2006: 83ff).
} 
the speaker is (at least partially) responsible for some act or state of the listener. And if this holds for the perlocutionary act, the whole locutionary-illocutionary-perlocutionary distinction should not be read as a distinction among gestures (whether physical or psychological or both), but rather, as one among the kinds of effects for which speakers may be ascribed responsibility.

\section{Did Austin exclude “non-serious” cases?}

I come now to the fourth assumption I have to comment upon, namely, that Austin's speech act theory unduly excludes "non-serious" cases.

Jacques Derrida has claimed that the possibility of non-seriousness in language use is ubiquitous (in fact, we never know whether a speech act is actually seriously performed) and that this undermines the whole speech-act theoretical enterprise. According to Derrida (1972), Austin overlooked this possibility or, more precisely, tried to sweep it under the carpet by excluding non-seriousness from consideration. So his speech act theory relies on flawed foundations. When Derrida leveled this criticism at speech act theory, his most natural respondent could only be John Searle, who replied that "non-serious" cases can indeed be studied by speech act theory or by an appropriate extension of it, and that Austin merely accidentally failed to do so (Searle 1977). It is interesting to notice that Searle shares at least one of Derrida's presuppositions, namely, that Austin should have dealt with "non-serious" cases.

But is it true that Austin unduly excluded "non-seriousness" (whether by mistake or by accident)? He excludes it just insofar as the serious/non-serious distinction is not a distinction between types of illocutionary acts, nor between felicitous vs. infelicitous illocutionary acts. Since his aim is to focus on the illocutionary level of the speech act, to the extent that he excludes "non-seriousness" he is justified in doing so. At the same time, precisely because the serious/non-serious distinction is not a distinction between types of illocutionary acts, Austin does not need to exclude "non-seriousness" from the concrete possibilities which are open to language users: Speech acts belonging to any illocutionary type may be performed either seriously or in any one of several "nonserious" ways. So, he recognizes the ubiquitous possibility of non-seriousness, or as he prefers to call it, “aetiolation”, but does not consider it as a threat to his project. It is just another dimension along which the uses of language may be studied.

Derrida's attack aims at a critique of the speaking subject: He wants to convey that it is not legitimate to assume that there is a well-identifiable speaking subject, having beliefs, desires, intentions and thus actually acting. Without such a subject no talk of speech acts would be legitimate either. But his attack does not really affect Austin's speech act theory, because speaker intention is not central to it. If actions are not gestures (including the formation of an intention as a psychological component), then undecidability or even lack of speaker intention does not prevent us from speaking of actions.

It is to be noted that John Searle is closer to Derrida than to Austin in believing that speech act theory needs a robust conception of the speaking subject. His debate with Derrida is about whether such a robust conception is possible. So he defends a speech act theory based on speaker intentions, that is, his own. The contrast between Derrida and Austin, on the other hand, is about whether a robust conception of the speaking subject is needed at all. Derrida believes that since no obust conception of the 
speaking subject is viable, speech act theory is undermined. But Austin's outline of a speech act theory does not rely on any such conception.

In concluding this section I would like to mention that if Austin had developed a theory of aetiolation himself, he would most likely not have employed an umbrellanotion of "pretending” or "doing as if" (which is Searle's proposed solution). From his preparatory notes, it appears that he conceived of aetiolation as affecting features of the speech act such as its source - for which he uses the more specific word "authority", possibly in the sense in which later on, Erving Goffman will use "author" (e.g. in his 1981) - , addressee, sense, and reference, by concealing, suspending, shifting or weakening them. ${ }^{7}$ Nowhere does he suggest that an aetiolated speech act is therefore a non-act or a merely pretended act. Rather, the resulting image of aetiolation may remind us of some of the processes which, in interdisciplinary research into language use, have recently been studied under the label of "mitigation" 8 .

\section{Some implications of Austin's claims}

After our explorations in HTW, what can we say about the contributions it offers to pragmatics?

We have seen that the performative/constative distinction is exploited in the proof by contradiction of the claim that all speech is action and that the analysis of performatives serves to introduce the conventional actions that are performed in speaking, that is, illocutionary acts. We have not tackled the meaning/force distinction directly (this would be a complicated matter, because in HTW nothing clear is said about meaning - which is perhaps the main defect of the book), but we have characterized the illocutionary dimension of language use as conventional in an unusual sense, that is, because of the conventionality of the effects it produces. What has been deemed a hasty mistake, namely, the conventionality of all illocutionary acts, appears now as a thoughtful philosophical claim. We have pointed out that the perlocutionary act presupposes action as responsibility rather than intentionally performed gesture, and have attempted to show that, accordingly, Austin's speech act theory does not presuppose a robust conception of the speaking subject.

Of course, we should also recognize that the claims I have attributed to Austin may have various shortcomings. Is Austin's proof by contradiction that all speech is action sound? Is his view of action correct? Above all: How can his idea that all illocutionary acts have conventional effects apply to assertion? I cannot tackle such issues here, because my aim has not been to discuss whether Austin was right, but merely, to clarify his claims. Instead, I would like to try to say what are the implications of the reading of HTW I have proposed: Why we should be concerned with the claims Austin makes, why we should consider them seriously and discuss them or try to test them by putting them to use.

${ }^{7}$ In a brief note, presumably written in 1951, Austin sketchily suggests to view quotation as aetiolation of authority, soliloquy as aetiolation of address, acting as aetiolation of both, joking as aetiolation of sense and fiction as aetiolation of reference.

${ }^{8}$ Mitigation attenuates the impact of the speech act on the receiver as well as its costs for the speaker. It has been studied by several linguists and sociolinguists since 1980, including Fraser (1980) and Caffi (1999). It has been said to suspend or weaken various aspects of the speech act, among which (according to Caffi) the relationship of the speech act to its deictic origin. 
Austin's claims have implications both for research into language use and for philosophy. Their main implications for research into language use are:

(1) that the role played in speech act theory and speech-act inspired discourse analysis by explicit performative utterances should be reassessed;

(2) that such a reassessment makes it viable to give non-trivial analyses of any text or discourse in terms of illocution.

It has sometimes been thought that Austin's theory is applicable only when explicit performative utterances can be used, or that utterances have illocutionary forces only insofar as these forces can be made explicit by performative verbs. Since explicit performative utterances are rarely used and the force of an utterance rarely corresponds to one and only one specific performative verb, it has often been deemed that the applicability of Austinian illocutionary acts is limited. But if, in considering illocution, we focus on its effects rather than on the means for achieving them, we see we can recognize the performance of an illocutionary act not only (classically) from the fact that it can be made explicit by a performative verb, but also from the kind of effect it brings about. So we might want to say that illocutionary acts are conventional because their effects are based on intersubjective agreement and not because they can be performed by means of explicit performative utterances. Rather, they can be performed by explicit performative utterances just because they are conventional in our sense: Only for acts having conventional effects, saying can make it so.

Conventional effects, based on intersubjective agreement, concern matters liable to defeasibility and cancellation such as rights, obligations, licenses, commitments. So we can find ways of describing illocution other than the lexicon of performative verbs, that is, directly describe the effect (often vague or hybrid) that the utterance "takes" on the local statuses of the interactants in an interactional sequence. This makes it viable to analyze the illocutionary dimension in any text or discourse, including informal conversation, written texts, fictional discourse, and discourse in the context of different cultures.

While performatives are rarely used in informal conversation, implicit negotiation about what each participant can do and should do or should expect from other participants is constantly present and draws on the dimension of illocution as I have characterized it. In writing, illocutionary effects are made available to any reader who takes the role of the addressee. In fictional discourse, most illocutionary effects affect fictional entities. Cultural differences may involve differences in the gamut of admissible illocutionary effects as well as in the procedures for bringing them about. Illocutionary effects may be associated with utterances smaller or larger than sentence size, they may be indicated with varying degrees of precision by linguistic illocutionary indicators and selected and made operative by the hearer's uptake (as manifested in verbal replies or nonverbal responsive behaviour), and they may also display varying degrees of intensity or strength, often in connection with politeness strategies. Illocution also provides a mediation between speech and many of its psychological and behavioural effects (which are perlocutionary). The distinction between illocution and perlocution enables us to keep both the conventional and the psychological or behavioural score of an interaction and monitor their reciprocal influence. Certainly all these matters are constantly studied in many fields of pragmatic research, but their 
connection with the illocutionary dimension of speech often goes unnoticed, while a greater awareness of it might, sometimes at least, be illuminating.

Turning to philosophy, I would like to outline three philosophical implications of Austin's HTW, which are highlighted by the reading I have proposed. They concern: Action and agency; the social contract; and ontology.

The conceptions of action and agency underlying Austin's speech act theory grant an unusually wide role to the ascription of responsibility. If responsibility is central to agency, identifying an action requires first identifying a state of affairs (its effect) and then correlating it with an agent (who is made responsible for it by his or her behaviour and circumstances). This broadens the range of things we "do", which cannot always be reduced to bodily movements made with an intention in mind.

Illocution sheds light on the nature of the social contract. Indeed, social order and social structure avail themselves of illocutionary acts or, in other words, of the delicate mechanisms producing local tacit agreement, which enable human creatures to create "conventional" states of affairs. The conception of illocution I have presented implies that local tacit agreement on what conventional states of affairs are in force is basic and does not require further foundations. As soon as it is seen that it is one of the main business of language to let human beings coordinate their behaviour and converge on assigning commitments or obligations and legitimate expectations to each other, thus creating conventional states of affairs, the social contract is no longer a mystery.

Finally, although Austin does not put forward metaphysical claims about "what there is", it is clear that if we admit of the conventional effects of illocutionary acts, we are committed to some kind of ontological pluralism. Conventional effects of illocutionary acts are states of affairs which may be said to exist, but by definition are not reducible to material, natural states of affairs. Moreover, an analysis of aetiolation as shifting or weakening features of the whole speech act might suggest to admit of fictional or virtual entities, which exist but, so to say, in weakened ways.

All this, I grant, is highly controversial, both by itself and in connection to the cognitive turn that for independent reasons has gained so much ground in linguistic pragmatics as well as in the philosophy of language (if not in philosophy tout court). But I hope it is also stimulating enough to be worth further consideration and discussion, and induce a reassessment of Austin's contributions.

A final comment. In the various ways I've been trying to illustrate, Austin gives us insights into the capacity of mankind for creating shared environments through language, not as a matter of transmitting anything from one head to the other or of causally influencing each other's mental states, but as a matter of establishing situations and roles and attributing local statuses to participants. Herein lies the power of human civilisation as opposed to "state of nature"; the power which alone makes it possible, on occasion, for someone weak and without weapons to be listened to and even obeyed, the power which makes it possible to conceive and pursue things such as social equality or solidarity and equal opportunities for genders, all of which would not be conceivable in a "state of nature" ethology. To acknowledge in theory and investigate such power is at the same time to foster it and defend it against the risk of regression into forms of social life based on brute force and coercion. 


\section{Acknowledgements}

This paper was read as a plenary lecture at the 9th International Pragmatics Conference, Riva del Garda, 10-15 July 2005. I thank the audience and particularly Mitch Green, Rob Stainton and Rukhmini Bhaya Nair for questions and comments. I have discussed my views on Austin's philosophy of language on various occasions with several colleagues, among whom I would like to thank in particular Anita Avramides, Christopher Gauker, Andreas Kemmerling and Paolo Leonardi. I thank Anita Avramides, Robyn Carston and Paolo Leonardi for commenting on a draft of this paper. I am very grateful to Jean Austin for her permission to cite from notes belonging to the manuscript of How to Do Things with Words not included in the published edition. This research was made possible by a joint grant of the Italian Ministry for Education, University and Scientific Research and the University of Trieste (PRIN 2003). The national project, on "Representation and Reasoning", was coordinated by Carlo Penco, University of Genova; the local project, on "Assertion, justification and inference”, was coordinated by me.

\section{References}

Austin, John L. (1956) A plea for excuses. Proceedings of the Aristotelian Society 57. Repr. in J.L. Austin 1970: $175-204$.

Austin, John L. (1957) Pretending. Proceedings of the Aristotelian Society, Suppl. Vol. 32. Repr. in J.L. Austin 1970: 253-271.

Austin, John L. (1962) How to Do Things with Words. Oxford: Oxford University Press. 2nd revised edition 1975.

Austin, John L. (1966) Three ways of spilling ink. The Philosophical Review 75. Repr. in J.L. Austin 1970: 272-287.

Austin, John L. (1970) Philosophical Papers (2nd ed.). Oxford: Oxford University Press.

Bach, Kent, and Robert M. Harnish. (1979) Linguistic Communication and Speech Acts. Cambridge, Mass.: M.I.T. Press.

Black, Max (1963) Austin on Performatives. Philosophy 38: 217-263.

Caffi, Claudia (1999) On mitigation. Journal of Pragmatics 31: 881-909.

Crary, Alice (2002) The happy truth: J.L. Austin's How to Do Things with Words. Inquiry 45: 59-80.

Derrida, Jacques (1972) Signature événement contexte. In J. Derrida, Marges de la philosophie. Paris: Minuit, pp. 365-93.

Forguson, L.W. (1966) In pursuit of performatives. Philosophy 41: 341-47.

Fraser, Bruce (1980) Conversational mitigation. Journal of Pragmatics 4: 341-350.

Goldman, Alvin (1970) A Theory of Human Action. Prentice-Hall. 
Goffman, Erving (1981) Footing. In Forms of Talk. Philadelphia: University of Pennsylvania Press, pp. 124-157.

Gu, Yueguo (1993) The impasse of perlocution. Journal of Pragmatics 20: 405-32.

Sbisà, Marina (1984) On illocutionary types. Journal of Pragmatics 8: 93-112.

Sbisà Marina (2001) Illocutionary force and degrees of strength in language use. Journal of Pragmatics 33: 1791-1814.

Sbisà, Marina (2006) Communicating citizenship in verbal interaction: Principles of a speech act oriented discourse analysis. In H. Hausendorf \& A. Bora (eds.), Analysing Citizenship Talk. Amsterdam: John Benjamins Publishing Company, pp. 151-180.

John R. Searle (1969) Speech Acts. Cambridge: Cambridge University Press.

John R. Searle (1979) Expression and Meaning. Cambridge: Cambridge University Press.

Searle, John R. (1977) Reiterating the differences: A reply to Derrida. Glyph. John Hopkins Textual Studies 1.

Strawson, Peter F. (1964) Intention and convention in speech acts. Philosophical Review 73: 439-460.

Yeager, Daniel (2006) J.L. Austin and the law. Lewisburg: Bucknell University Press. 